\title{
Fracture analysis of concrete gravity dam under earthquake induced loads
}

\section{${ }^{1}$ ABBAS MANSOURI; ${ }^{2}$ MIR AHMAD LASHTEH NESHAEI; ${ }^{3}$ REZA AGHAJANY}

\author{
${ }^{1}$ Civil Engineering, Islamic Azad University (South Branch of Tehran)Tehran, Iran \\ ${ }^{2}$ Civil Engineering, University of Guilan, Rasht, Iran \\ ${ }^{3}$ Civil Engineering, Islamic Azad University, (North Branch of Tehran), Tehran, Iran \\ E-mail: rezaaghajany@yahoo.com \\ Tel: +98.9111281372
}

\begin{abstract}
In this paper, seismic fracture behavior of the concrete gravity dam using finite element (2D) theory has been studied. Bazant model which is non-linear fracture mechanics criteria as a measure of growth and smeared crack was chosen to develop profiles of the crack. Behavior of stress - strain curves of concrete as a simplified two-line, dam and reservoir system using the formulation of the Euler - Lagrange was chosen. According to the above models, Koyna concrete gravity dam were investigated by the 1967 earthquake record. The results provide profiles of growth and expansion first with the effects of reservoir and second without it. Comparison of the obtained results shows good agreement with the works of the other researchers. @ JASEM
\end{abstract}

Keywords: Seismic fracture; Smeared crack; Non-linear fracture mechanics; Concrete gravity dam.

The seismic behavior of concrete dams has been the subject of extensive research during the past decade concerning dam safety during earthquakes. Chopra $e t$ al (1972), studies seismic behavior of dam's crack path by using linear elastic analysis. The analysis shows, places that are in damage or and risk of the concerning stability of structure. Pal (1976) was the first researcher who examined Koyna dam by using non-linear analysis. In this research, assuming no effect of reservoir, being rigid foundation, smeared crack model use for crack expansion and strength criteria to crack growth, Koyna dam was analyzed and was shown that the results of material properties and element size are very sensitive. Figure 1(a) crack zone in the dam of which resulting from this analysis are shown. Skrikerud (1986) studied concrete dams through a case study on Koyna dam and by employing discrete crack for crack growth and strength criteria for crack expansion. In their study the growth of crack at each step of growth, the length of the crack tip element was considered that this is the final results were effective. He interpreted the results of their model, due to expansion mismatch with the cracking in their analysis of real crack in the dam, no match Foundation and reservoir interaction and lack of real values of characteristic parameters dam announced. Crack profiles from the analysis left in Figure 1(b) are presented. El-Aidi and Hall (1989) did a research on seismic fracture of Pine flat dam. Smeared crack model and strength criteria for crack expansion and growth were used. In their analysis is considering the reservoir - dam and foundation - dam interaction was crack profile presented. Figure 1(c), cracking in the dam will provide analysis. Fenves and Vargas-Loli also studied Pine flat dam by using fracture mechanics criteria for crack growth and smeared crack model to crack expand (Uang and Bertero, 1990). They apply different coefficients of Taft earthquake record, regardless of the effect by foundation; Pine Flat dam in two cases with and without the effect of the reservoir was analyzed. In this study the effect of hydrodynamic pressure on the seismic behavior in the dam with the crack profiles presented. The results of this analysis were shown in Figure 1(d). Bhattacharjee and Leger (1994) presented detailed results of their study on nonlinear analysis models of gravity concrete dams. Nonlinear Behavior in Seismic their smeared crack models were used. In their analysis, dynamic and static results of this model have been compared to laboratory results and cracks formed in Koyna gravity dam and approved. Results from this analysis in Figure 1(f) can be seen. Ghaemian and Ghobarah (1999) to assess the seismic behavior of concrete dams in the two-dimensional space of the smeared crack model presented in 1993 and 1994 by leger and Bhattacharjee used. 2D seismic fracture behavior of the Koyna dam were examined by Ganglia et al, (2000).In their studies smeared crack model for crack growth and non-linear fracture mechanics criteria for the expansion of cracks were used. Lohrasbi and Attarnejad (2008) also used fracture mechanics theory in their analysis, to evaluate the smeared crack model and discrete crack model. Nonlinear seismic behavior of the Koyna dam by considering Dam and Reservoir interaction examined by Mirzabozorg and Ghaemian (2005). They analysis Koyna dam under dynamic loading, defined fracture mechanics of the fracture region and the smeared crack model. Through an article published in 2005, Calayir and Karaton (2005) evaluated the response of seismic fracture in gravity concrete dams. In their own study with regard to dam and reservoir interaction, Koyna dam to the finite element method with Lagrange - Lagrange formulation, analysis and the crack profiles growth were presented. Results from this analysis in Figure 1(e) can be seen. Cai et al 
fractures in concrete dams were examined (2008). They evaluate the fracture behavior of dam using smeared crack models to develop cracks; dam in South Africa and Koyna dam the finite element method were analyzed and in their study to review the effect of fracture parameters on the seismic behavior of concrete dams began.

Figure 1(h) crack mapping of the Koyna dam with scale 1:150, by using laboratory models that was on the trembling table and the reference (Hal, 1988) was taken, were presented. Figure $1(\mathrm{~g})$, the real crack model profiles in the Koyna dam was extracted from the reference (Saini and Krishna, 1974), is shown.

Figure 1 is a visible growth profile of crack left from analysis done by researcher. What these studies show is that all dams crack in severe earthquakes and because of nonlinear behavior of concrete against dynamic loads, nonlinear analysis is required to examine durability and evaluate the safety of gravity concrete dam.

The presented results reveal that growth and expansion of crack profile occur in dam heels and changing areas of slope. Of course in dams like

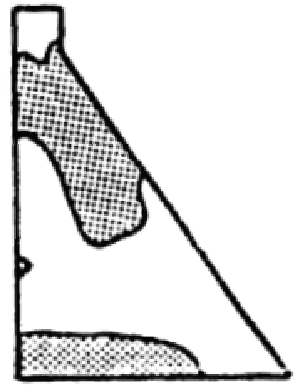

(d) Vargas-loli

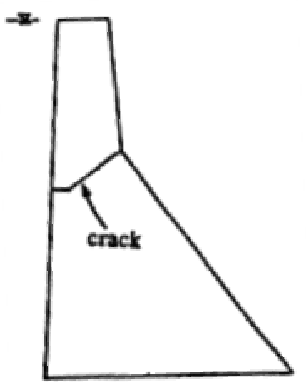

(h) Experimental model

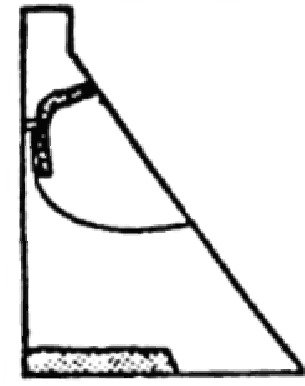

(c) El-Aidi

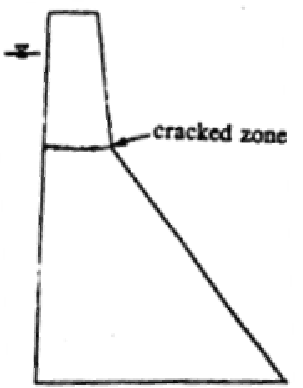

(g) Real model

Koyna with vertical upper part, cracks were found in upper part. Shows research in the field of seismic behavior of concrete dams, is very limited practical results on the structural strength of concrete gravity dams under severe earthquake. Koyna dam and Pine flat dam are classic examples that are available the results of fracture analysis. Koyna dam is one of a few concrete dams that have experienced a destructive earthquake. In this paper, study the nonlinear fracture behavior of concrete gravity dams under earthquake conditions. First, presented smeared crack model with the behavior of concrete under dynamic loads and fracture of dams. Secondly, Seismic behavior of concrete gravity dams was assessed with non-linear analysis to Koyna dam with regard dam - reservoir interaction and without reservoir using finite element $2 \mathrm{D}$ method and presented results of analysis. From the results it is concluded that both the upstream and downstream faces of the dam are predicted to experience cracking through the upper part of the dam, which is consistent with the observed prototype behavior. Comparison analysis was done showed that the reservoir effect cannot be waived.

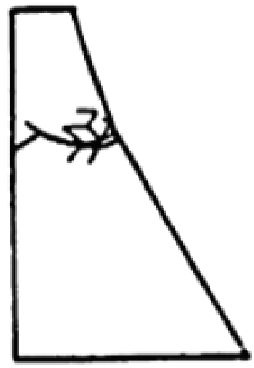

(b) Skrikerud

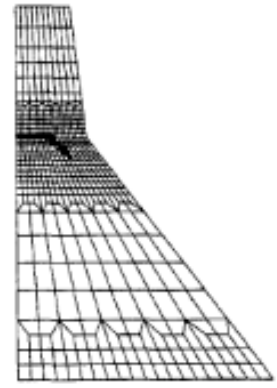

(f) Bhattacharjee and Leger

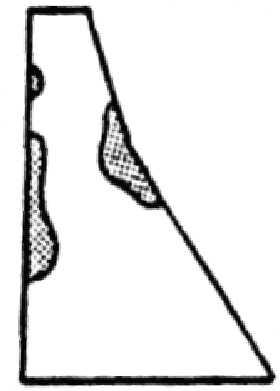

(a) $\mathrm{Pal}$

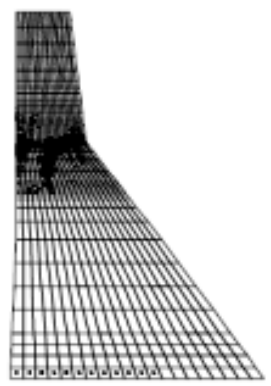

(e) Calayir and Karaton

Figure 1: Past investigations into cracking profile in gravity dams.

Euler - Lagrange Formulation for Dynamic Interaction of Dam-Reservoir Systems and Boundary Conditions: Different methods for dam and reservoir modeling are used. The Euler - Lagrange model is one criteria to used. In this research, the relations of Euler - Lagrange for dam and reservoir modeling system is investigated.

In Figure 2, the dam and reservoir boundary condition is presented. According to the finite element theory equations governing the dam is as follows (Kucukarslan, 2003):

$$
[M]\{r\}+[C]\{r\}+[K]\{r\}=-[M][J]\left\{a_{g}\right\}
$$

In this equations, $[\boldsymbol{M}]=$ Mass matrix, $[\boldsymbol{C}]=$ Damping matrix, $[\boldsymbol{K}]=$ Structural stiffness matrix, $\{\boldsymbol{r}\}=$ Displacement vector of relative nodal, $[\boldsymbol{J}]=$ Unit matrix, $\left\{\boldsymbol{\alpha}_{g}\right\}=$ Anchor acceleration vector. 
Equation governing the distribution of hydrodynamit. pressure in the fluid environment is well known Helmholtz equation by two relations in which presented by the equation below:

$$
\nabla^{2} \mathrm{p}=\frac{1}{\mathrm{c}^{2}} \frac{\partial^{2} \mathrm{p}}{\partial \mathrm{t}^{2}}
$$

In Equation (2), $\mathrm{P}=$ the fluid pressures, $\mathrm{C}=$ the speed of sound in the fluid.

Four boundary conditions are used to define the reservoir as follows.

1. Free surface

$\boldsymbol{p}=\mathbf{0}$

2. Remote

$$
\frac{\partial_{p}}{\partial_{n}}=-\frac{1}{c^{2}} \dot{p}
$$

3. Interaction

$$
\frac{\partial p}{\partial n}=-\rho \alpha_{g}^{n}
$$

Bottom
$\frac{\partial p}{\partial n}=-\rho a_{g}^{n}-q \frac{a_{p}}{\partial_{t}}$

Boundary

In this Equations, $\boldsymbol{\alpha}_{s}^{n}=$ Dam Acceleration, $\boldsymbol{\alpha}_{g}^{n}=$ Ground Acceleration, $\boldsymbol{n}=$ Vector perpendicular, $\boldsymbol{\rho}=$ Fluid density. Value of acceleration created in the reservoir, is related to the amount of dam acceleration. $\boldsymbol{q}=\frac{\rho_{1}}{\boldsymbol{\rho}_{2} \boldsymbol{C}_{2}}$, where: $\boldsymbol{\rho}_{1}=$ fluid density, $\boldsymbol{\rho}_{2}=$ Dam density, $\boldsymbol{C}_{\mathbf{Z}}=$ speed of sound.

Boundary Considering the boundary conditions and fluid equations, the relationship matrix in the reservoir is formed as follows:

Boundary $[G]\{p\}+[L]\{p\}+[H]\{p\}=-[B][J]\left\{a_{g}\right\}$

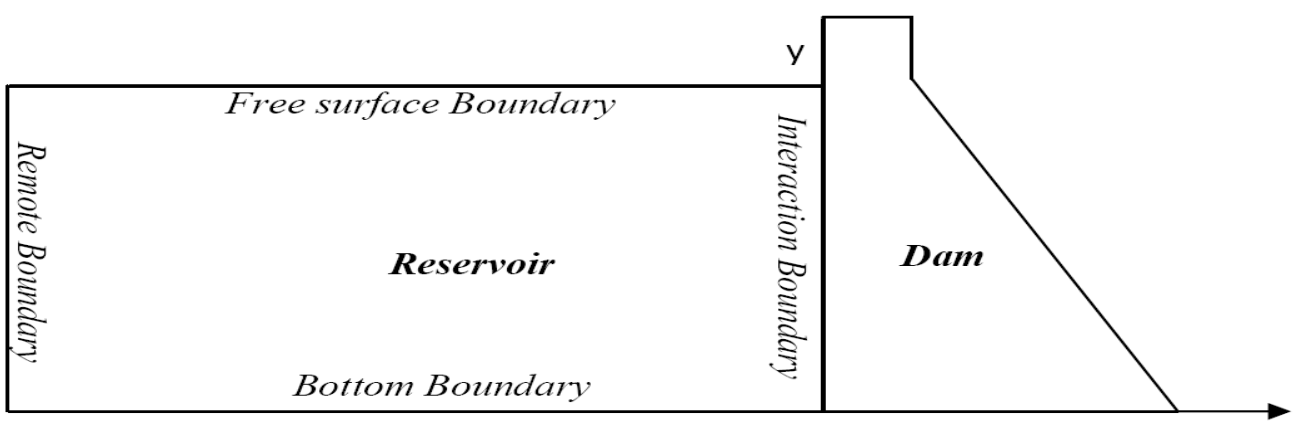

Figure 2: dam and reservoir Systems

in the concrete as a series of parallel cracks in the width of element which is visible in figure 3 .

Where: $[\boldsymbol{G}]=$ Fluid mass matrix, $[\boldsymbol{L}]=$ Damping matrix, $[\boldsymbol{H}]=$ Fluid stiffness matrix, $\{\boldsymbol{p}\}=$ Hydrodynamic pressure vector, $[\boldsymbol{U}]=$ Unit matrix, $\left\{\boldsymbol{a}_{g}\right\}=$ Anchor Acceleration vector.

Equations 1 and 7 are the equations of fluid and dam respectively. When these two media are placed in the vicinity of each others, the interaction effects between
Naturally, when a substance is placed under loading which is beyond its strength, cracks begins at the point where substance has no defect or substantial non-uniformity. Using continuum mechanics, when a sample becomes a model, it is usually supposed that there is no defect or non-uniformity in the substance.

Therefore in such models, dissipation potentials, known as submission or rupture model, is often used to form crack and expand it.

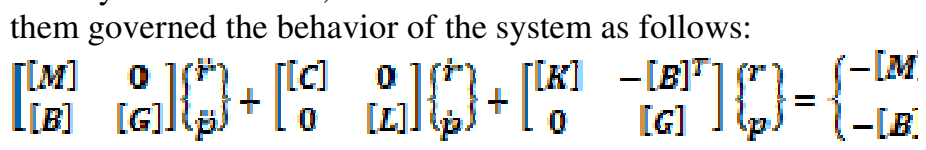

Smeared Crack Model: Smeared crack model is one of the many models that presented for concrete which is used in most of the finite element soft wares. Physically, smeared crack model can be expressed in a series of tiny cracks. This is defined by the maximum main tensile stress.

When a crack is formed, a local coordinate define in a way that one of the axes is set perpendicularly to the surface of the crack. Then for these coordinate axes, a law of perpendicular strain-stress with strain softening parameter is considered. This model shows the crack

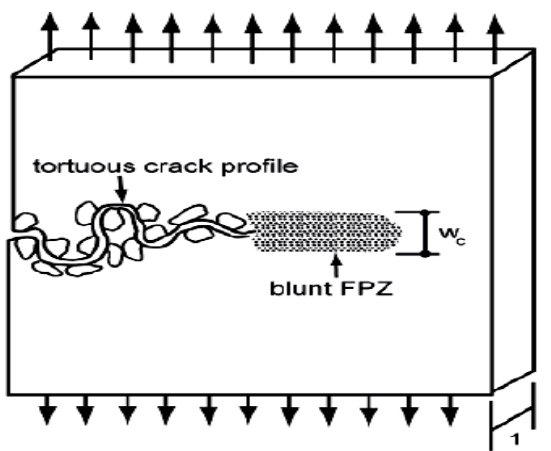

Figure 3: Smeared crack model (Bhattacharjee and Leger, 1992).

Rupture direction, is defined by potential derivative according to stress or strain tensor. Loss potential can be either a function of stress or strain (Kolari, 2007). In smeared crack model, loss potential 
is a function of stress. This means that crack happens when the stresses reach the level of submission. Also crack levels which are perpendicular to the maximum, are regarded as the tensile main stress. As a result in the state of compressive stress, no damage is recorded.

As stress increases inelastic strains happen and concrete becomes soft. At any point, after the maximum compressive strength of concrete, initial slope is parallel to loading slope. When the unloading

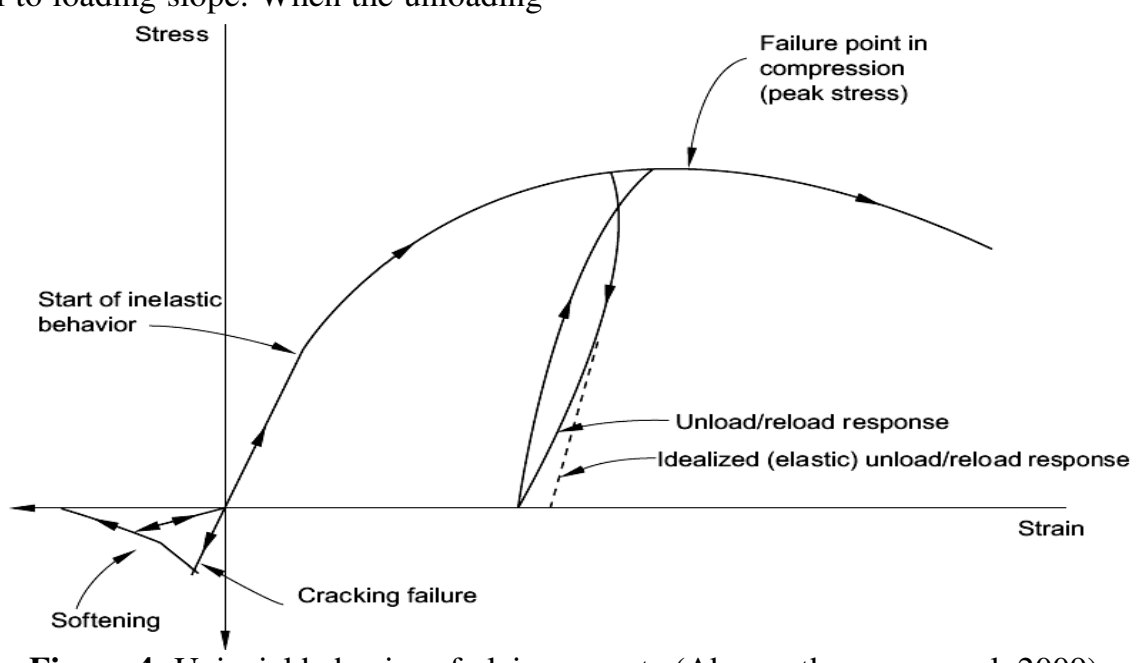

Figure 4: Uniaxial behavior of plain concrete (Abaqus theory manual, 2009).

Fracture Model: Choosing a proper fracture model for modeling the behavior of concrete against the applied loads is the important step in examining the behavior of concrete dams under dynamic loads. Philosophy of dams design against seismic loads is proposed as a linear elastic behavior under operating base earthquake, $\mathrm{OBE}^{1}$. However, under severe earthquake as maximum credible earthquake, $\mathrm{MCE}^{2}$, some cracks are formed in such structures where the application of nonlinear analysis in evaluating the safety of existing dams or stability of damaged under destructive earthquakes present itself more visibly. Nonlinear behavior models in two dimensional modes are used in the analysis of seismic concrete dams.

The first criterion used in most of the researches and analyses was strength criterion which was employed for presenting growth and expansion profile in concrete dams in 1970s (Cai et al, 2008). According to this criterion, crack occurs whenever the major tensile stresses in crack sheet exceed the tensile strength of concrete. The inability of this criterion in calculating shear stress and exclusive calculating of stress in crack sheet are among the weaknesses of this method. Of course this theory is applied in girder with low depth which regarding the fact that concrete dams are considered as deep girder, final responses are not sufficiently accurate.

According linear elastic fracture mechanics criteria, development process of crack and its growth

1 Operating Base Earthquake

2 Maximum Credible Earthquake direction changes (strain - stress) the concrete response is to the maximum elastic tensile stress and then crack mechanism occurs. Than as a result concrete is damaged. In this state, with the help of reducing elastic hardness, a model can be made out of crack unfolding. If the compressive stress is applied again, by returning to zero, the cracks will be closed completely. Figure 4 shows the behavior of concrete when placed under compressive and tensile stress. occur only at the peak of crack and the rest of elastic element remains and behaves linearly. This method is applicable in ordinary structure in which damaged area is relatively small. But using nonlinear fracture mechanics model is more suitable in huge structures such as concrete dams where the damaged area is relatively big. This method is established on the base of energy relations. In the field of fracture mechanics two models have been presented based on Hillerborg (1978) and Bazant (1983) theories. According to the model presented by Hillerborg in 1976, damaged area is considered as imaginary crack at the peak of the real crack. In 1983; Bazant showed that growth and expansion process of crack occur on a stripe. In the present study, Bazant smeared crack model is used in studying Koyna dam.

In order to define fracture mechanics criterion, fracture energy parameter is employed this is equal to the area under the stress-strain graph and can be calculated through the following relation:

$G_{f}=w_{\sigma} \int_{0}^{\varepsilon} \sigma(\varepsilon) d \varepsilon$

In this relation $w_{c}$, is the width of stripe in which the fracture process occurs; $\sigma$ stress and $\varepsilon$ strain.

In nonlinear fracture mechanics models, definition of curve softening is effective in drawing crack profile. This is because of large influences this parameter has on the results of numerical calculations. In this analysis, strain- stress curve is regarded as bilinear which is shown in figure 5 . 


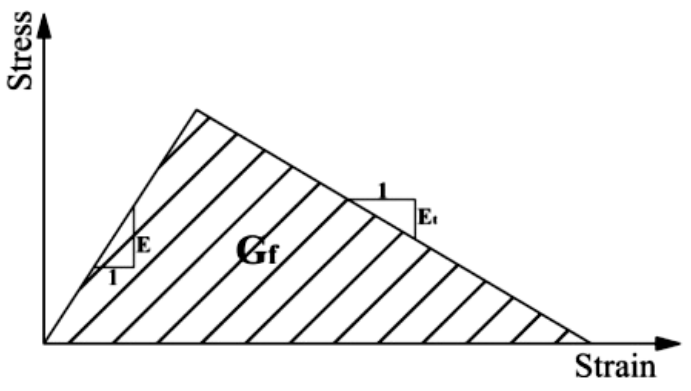

Figure 5: Complete stress- strain curve in tension.

The relation between strain-stress in materials is as following:

$$
\begin{aligned}
& \{a]=[D]\{\varepsilon] \\
& \left\{\sigma_{n}, \sigma_{p}, \tau_{n p}\right\}=[D]\left\{\varepsilon_{n}, \varepsilon_{p}, \gamma_{n p}\right\}
\end{aligned}
$$

In which $[D]$ is matrix of material behavior and $\sigma$ stress vector and $\boldsymbol{\varepsilon}$ strain vector in accordance with stress. In linear elastic part, this matrix is defined as follows:

$$
[D]=\left(\begin{array}{ccc}
\frac{E}{1-v^{2}} & \frac{E}{1-v^{2}} v & 0 \\
\frac{E}{1-v^{2}} v & E+\frac{E}{1-v^{2}} v^{2} & 0 \\
0 & 0 & G
\end{array}\right)
$$

In softening behavior, according to the axis of local coordinate presented in figure 6 , the matrix of material behavior when cracking takes place in the direction of local coordinate $\mathrm{n}$ is calculated as follows:

$$
[D]=\frac{E}{1-\eta \nu^{2}}\left(\begin{array}{ccc}
\eta & \eta v & 0 \\
\eta v & 1 & 0 \\
0 & 0 & \beta G
\end{array}\right): \eta=\frac{E_{t}}{E}
$$

$$
0 \leq \beta \leq 1
$$

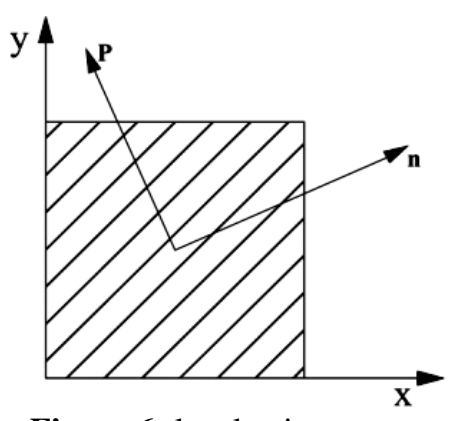

Figure 6: local axis system.

Here, $E=$ elastic modulus; and $v=$ Poisson's ratio and $\eta=$ ratio between the softened Young's and $\boldsymbol{G}=$ shear modulus; $\beta$ is the shear retention factor representing the extent of aggregate interlock on the crack surfaces. The shear retention factor $\beta$ has the following implications: when material is in the linear elastic range $\beta=1$ and when the concrete is in the softening range $0 \leq \beta \leq 1$, meaning that elastic aggregate interlock effects are assumed after cracking and; $E_{t}$, in the direction normal to a fracture plane.

\section{Analysis of Koyna Dam}

In this paper, seismic behavior of Koyna dam was examined through dynamic analysis of Koyna dam under acceleration mapping of Koyna earthquake which was recorded in 1967 and presented in figure 8. In this analysis Koyna dam, in two cases with and without the reservoir was analyzed. In this analysis, regard of dam-foundation interaction, Euler-Lagrange formulation was employed in reservoir modeling. Fracture area was defined by using nonlinear fracture mechanics criterion, developing cracks, smeared crack model was used. According to above-mentioned hypotheses, Koyna dam was modeled and analyzed by finite element $2 \mathrm{D}$ and plane stress conditions in with the help of Abaqus software (Abaqus theory manual, 2009).structure is modeled by the 3720 elements four node plane strain CPE4R; and reservoir modeled by used of acoustic elements four node AC2D4.

The Koyna concrete gravity dam, $103 \mathrm{~m}$ high, is located on the Koyna River in the west of the Indian Peninsula. In 1967, a 6.5-magnitude earthquake shook the region with maximum acceleration measured at the foundation gallery of $0.5 \mathrm{~g}$ and $0.35 \mathrm{~g}$ in horizontal direction normal to the dam axis and in the vertical, respectively.

The material parameters adopted in the analysis are shown in Table 1 . The concrete characteristic parameters adopted in the analysis are: Modulus of elasticity $=31.6 \mathrm{GPa}$; Density $=2643 \mathrm{Kg} / \mathrm{m}^{3} ;$ Damping ratio $=0.03 ;$ Compressive ultimate stress $=24.1 \mathrm{MPa}$; Poisson's ratio $=0.2$; Tensile strength $=2.41 \mathrm{MPa}$; Fracture energy $=250 \mathrm{~N} / \mathrm{m}$. The following data is considered for the fluid domain: Bulk modulus = $2.1 \mathrm{GPa}$; Mass density $=1000 \mathrm{Kg} / \mathrm{m}^{3}$.

Table 2 presents the Dimensions used in the finite element model and analysis. The dam structure has crest width of $14.8 \mathrm{~m}$, bottom width $70 \mathrm{~m}$, width of dam at the level of initial notch $19.25 \mathrm{~m}$ and the tallest of monoliths which is $103 \mathrm{~m}$. In order to determine the hydrodynamic pressure on the dam due to horizontal ground motion under the assumption of infinite reservoir, Sommerfeld truncation boundary condition (Kucukarslan, 2003) was applied at a distance L $\approx$ $3 \mathrm{H} \approx 300 \mathrm{~m}$ from the dam $(\mathrm{L}=$ reservoir width and $\mathrm{H}$ $=$ Dam height) (Chopra, 1967).The depth of the reservoir is $91.75 \mathrm{~m}$. Finite element model for the dam - reservoir system is given in figure 7 .

Table 1. Properties of materials.

\begin{tabular}{cc}
\hline Density of concrete $\left(\mathrm{Kg} / \mathrm{m}^{3}\right)$ & 2643 \\
\hline Fracture energy $(\mathrm{N} / \mathrm{m})$ & 250 \\
\hline Damping ratio $\xi$ & 0.03 \\
\hline Poisson's ratio $v$ & 0.2 \\
\hline
\end{tabular}




\begin{tabular}{cc}
\hline Tensile failure stress $(\mathrm{MPa})$ & 2.41 \\
\hline Compressive ultimate stress $(\mathrm{MPa})$ & 24.1 \\
\hline Modulus of elasticity $(\mathrm{GPa})$ & 31.6 \\
\hline Bulk modulus of fluid $(\mathrm{GPa})$ & 2.1 \\
\hline Density of fluid $\left(\mathrm{Kg} / \mathrm{m}^{3}\right)$ & 1000 \\
\hline
\end{tabular}

Table 2. Dimensions of the model $(m)$.

\begin{tabular}{cc}
\hline Dam height $(m)$ & 103 \\
\hline Crest width $(m)$ & 14.8 \\
\hline Bottom width $(m)$ & 70 \\
\hline Width of dam at the level of initial notch $(m)$ & 19.25 \\
\hline reservoir height $(m)$ & 91.75 \\
\hline reservoir width $(m)$ & 300 \\
\hline
\end{tabular}

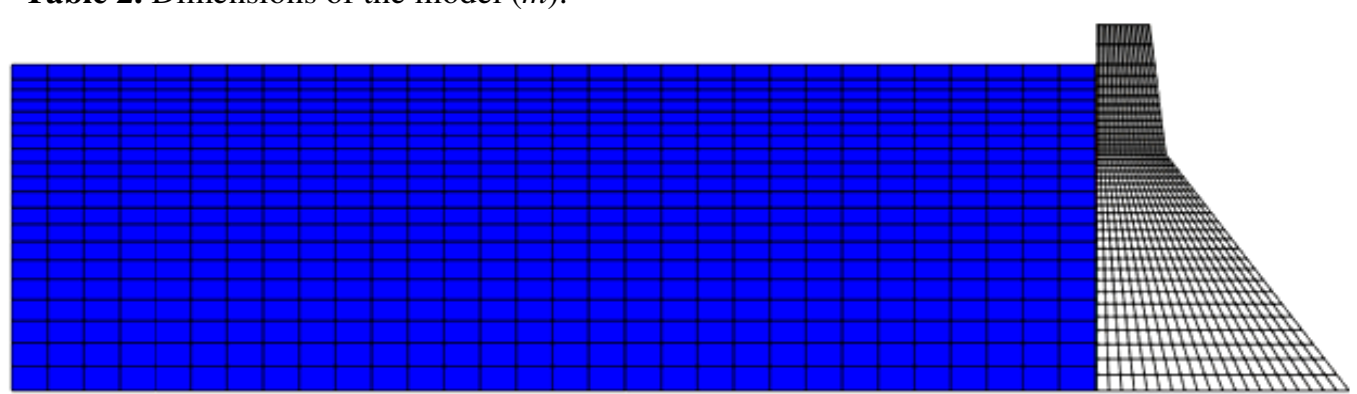

Figure 7. Finite element model of the Koyna dam - reservoir system.
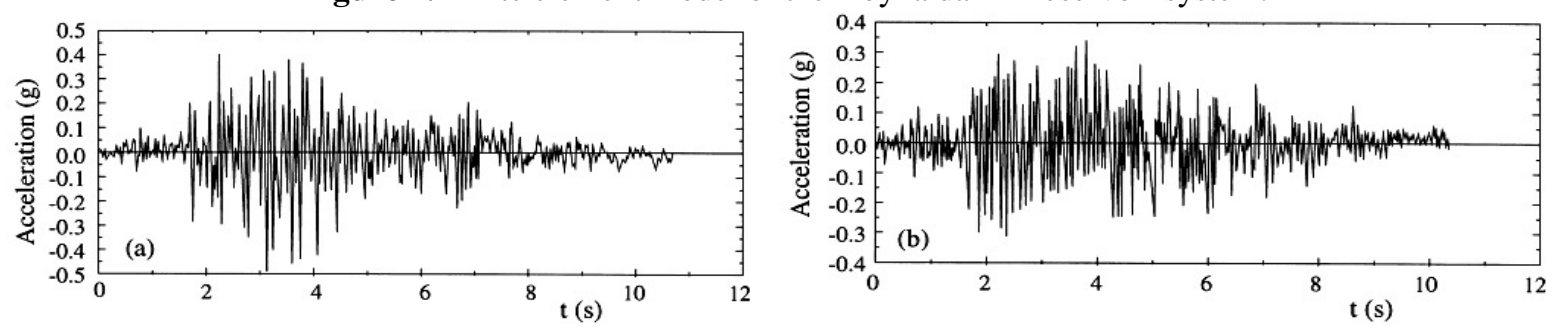

Figure 8. The Koyna accelerograms. (a) Transverse component and (b) vertical component.

Analysis of Koyna Dam and Reservoir Interaction

In this section, according to the assumptions that were presented, to examine responses Koyna dam in case the intended reservoir effect is to be paid. History of relative displacement of dam crest to the dam base is brought in figure 9. Observed maximum displacement for dam crest is 45 millimeter. History of vertical displacement of dam is presented in figure 10. In this graph maximum displacement of dam crest is 14 millimeter.

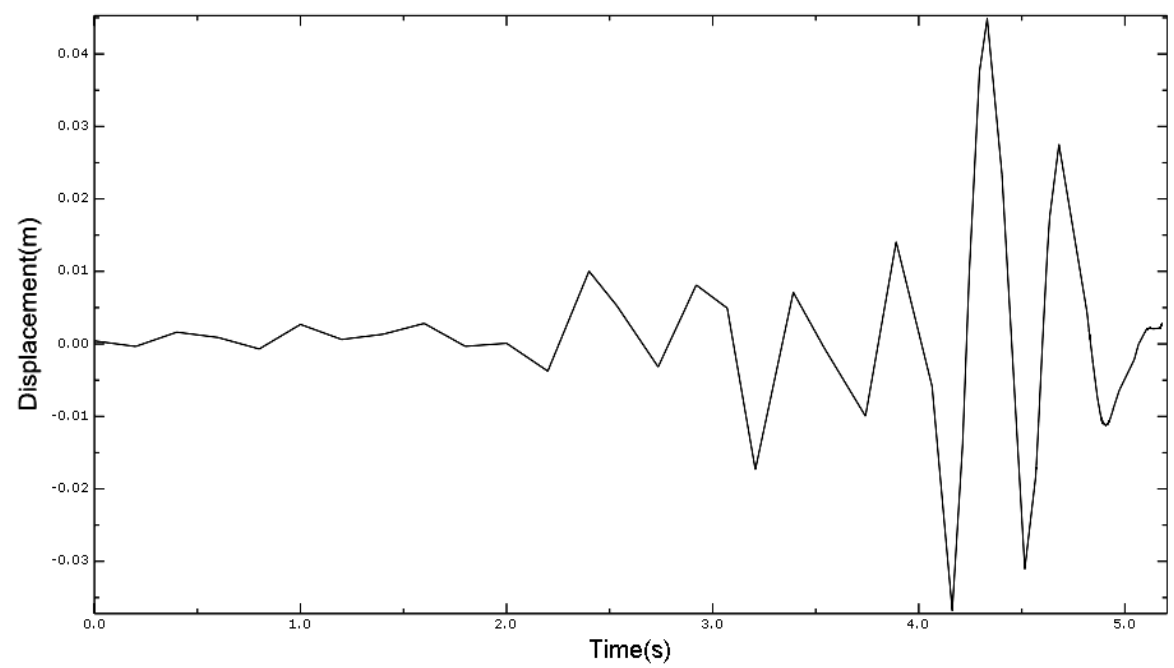

Figure 9. Time history graphs of horizontal displacement of dam crest to the base. 


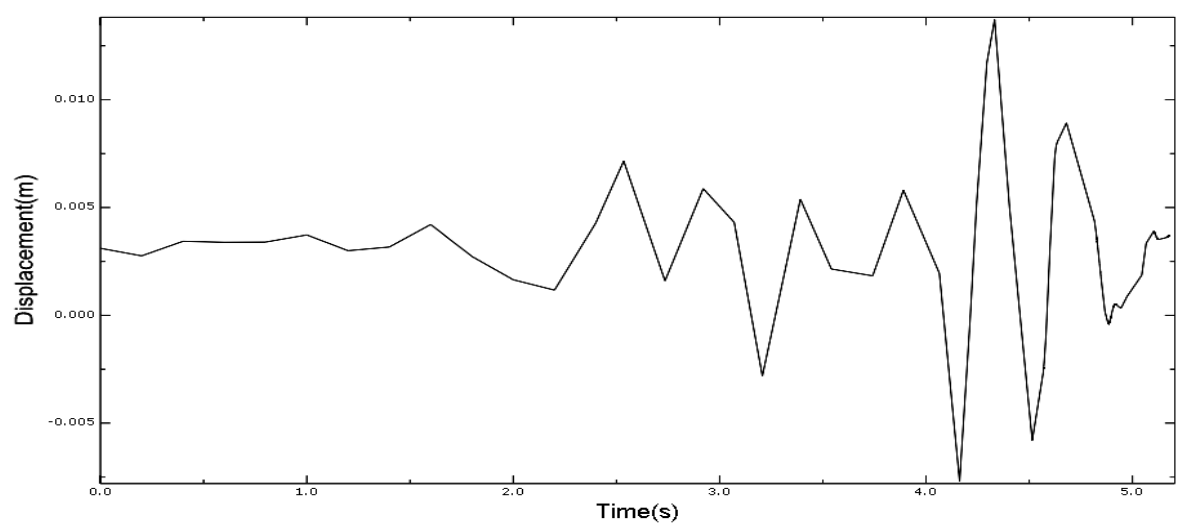

Figure 10. Time history graphs of vertical displacement of dam crest to the base.

Analysis of crack growth in terms of time was investigated. According to figure 11, the first elements in dam heels were damaged at the time of $3.78 \mathrm{sec}$ and crack was observed in this area. After that and at the time of $3.90 \mathrm{sec}$ first cracks were formed in changing areas of slope. With the continuation of decomposition and passage of time more elements cracked and it was observed that the fracture area expanded more. At the time of $4.37 \mathrm{sec}$, crack begins to grow from upper part and moves toward lower part .These cracks lead to instability and destruction of structure.

\section{Analysis of Koyna Dam without Reservoir}

In this section the results of Koyna dam analysis in the case regardless of the reservoir effect has been offered. Figure 12, time history graphs of vertical displacement of dam crest to the base without the reservoir shows, that this chart can be downloaded in this case the maximum vertical displacement is $10 / 50 \mathrm{~mm}$. Response of horizontal displacement of dam crest to the base regardless by the reservoir is presented in Figure 13. As in the history a graph of horizontal displacement of dam crest to the base is has observed Maximum displacement dam is about 28 $\mathrm{mm}$.

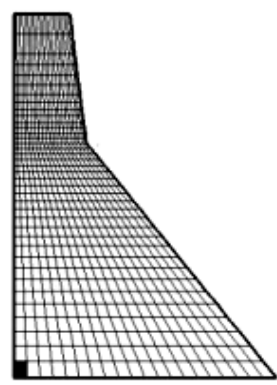

$\sec 3.78$

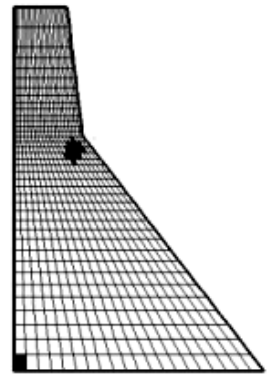

$\sec 3.99$

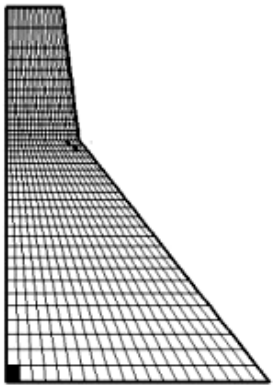

$\sec 3.90$

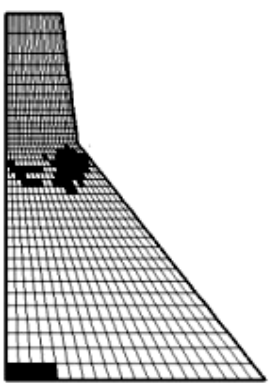

$\sec 4.37$

Figure 11. Cracking cases in the dam at four selected times.

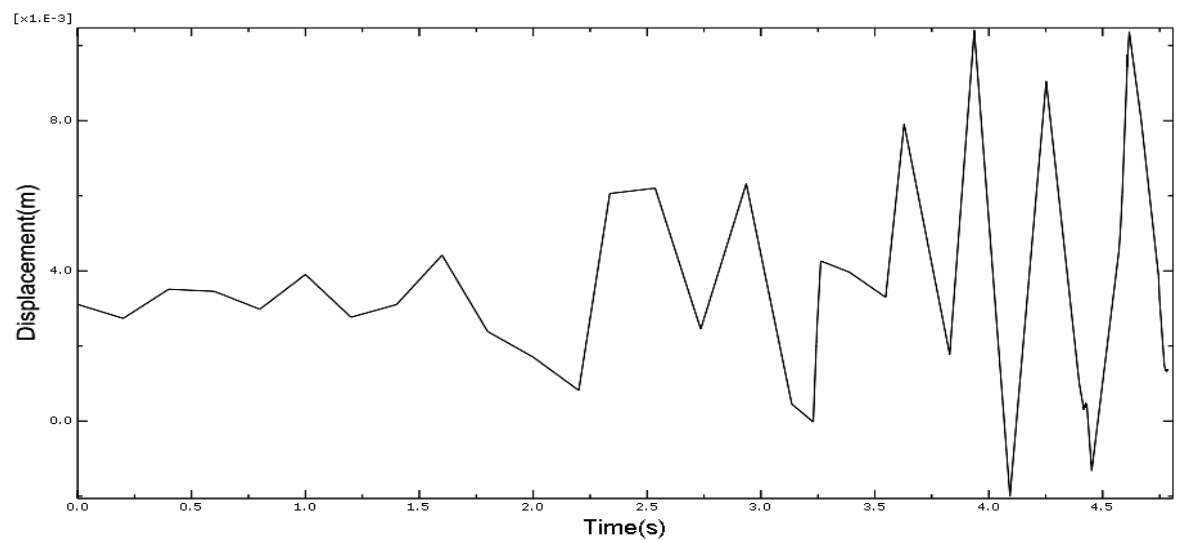

Figure 12. Time history graphs of vertical displacement of dam crest to the base. 


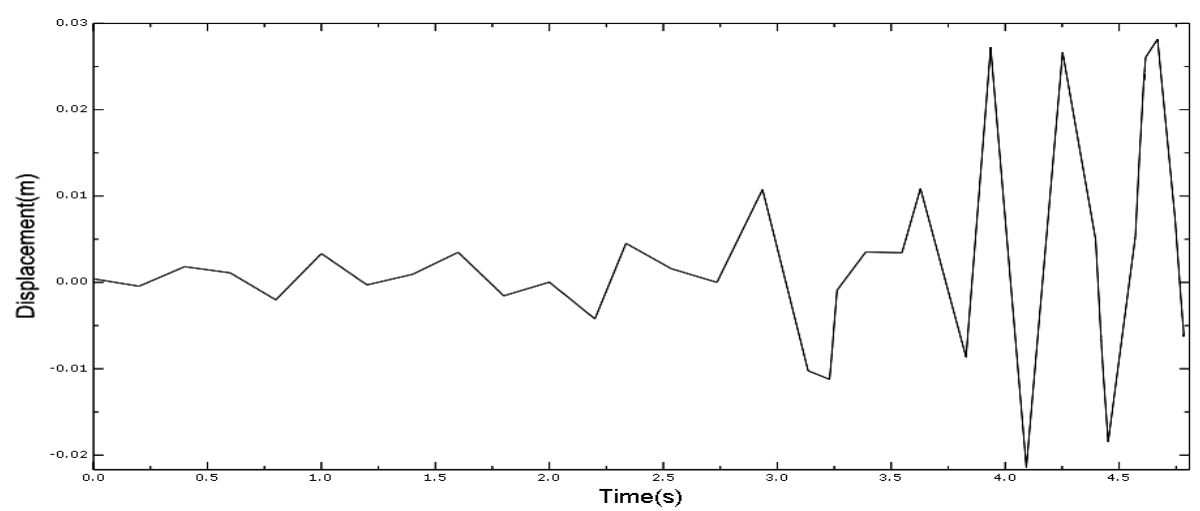

Figure 13. Time history graphs of horizontal displacement of dam crest to the base.

This section Examine the growth in cracking of Koyna dam in the case has not been without reservoir consideration to be paid is presented in Figure 14. Time of 3.18 seconds in the first crack can be seen in the dam heels. In 3.79 seconds at the dam heel of crack to grow. Observing the Figure 14 shows time of 3.89 seconds in the first cracks in the slope changes of the dam can be observed. Furthermore next time means 4.32 seconds more elements at the cracking of slope changes.

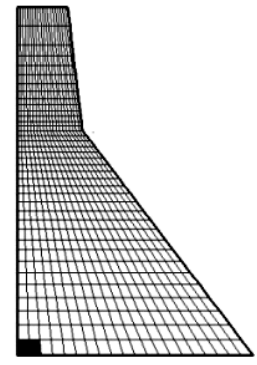

$\sec 3.18$

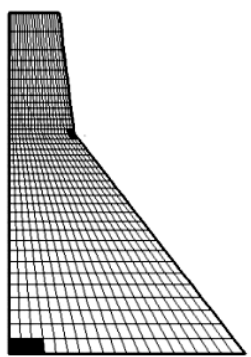

sec 3.89

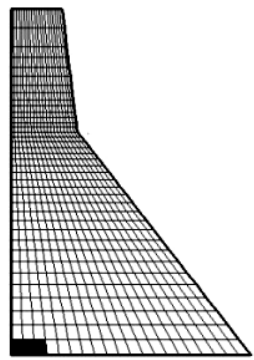

$\sec 3.79$

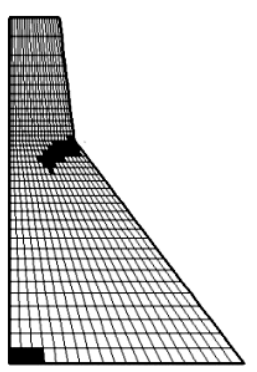

$\sec 4.32$
Figure 14. Cracking cases in the dam at four selected times.

In figure 15 , a comparison of crack growth has been made between two conditions of dam decomposition with reservoir and without it which through the study of cracked elements, the effects of reservoir on the presented results can be observed. (a)

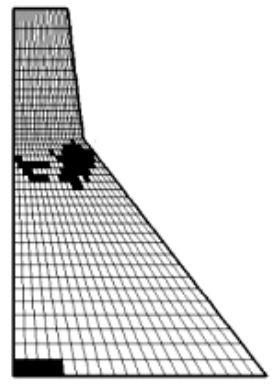

(b)

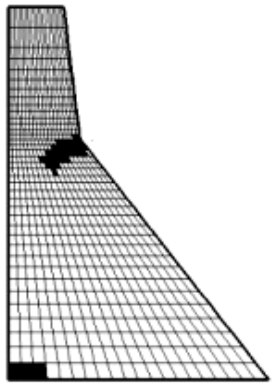

Figure 15. Crack profiles of the Koyna dam. (a) Including dam-reservoir interaction. (b) Without reservoir.

\section{Conclusion}

In this research interaction of dam and reservoir under earthquake was examined by employing nonlinear fracture mechanics criterion and smeared crack model of develop profiles of the crack. The results, through analysis in conditions of dam decomposition with reservoir and without it, the following conclusions were reached:

1. By comparing the results with other researchers it shows a fairly good agreement between this study and the others references: (Guanglun et al, 2000), (Calayir and Karaton, 2005), (Cai et al, 2008), (Hal, 1988), (Saini and Krishna, 1974), and therefore the philosophy of the nonlinear fracture mechanics criteria and smeared crack models at proper seismic behavior of concrete gravity dam seems to be confirmed. The obtained results of the analysis of Koyna dam considering interaction between dam and reservoir shows there are three vulnerable points: dam heels, changing areas of slope and some areas in upper part in which there are most of the crack elements. The results obtained in the analysis of Koyna dam regardless of reservoir effect on the dam, shows cracks in the heel areas of the dam, where the slope change. The results from analyses can be seen in damaged areas and the number of damaged elements in the case of interaction between dam and reservoir intended effect was bigger than effect of dam alone. Therefore it is important to attend the hydrodynamic pressure on concrete dam. 
2. Dynamic analysis was used in the smeared crack tohaemian, M. and Ghobarah, A (1999). " Nonlinear extend crack and the non-linear fracture mechanics criteria for crack growth profiles is indeed the function of profile material, especially fracture energy and behavior of materials.

3. Being given specific structures such as concrete gravity dam, which provide great scope area for fracture energy according to the various references and considering the importance of this parameter with the behavior of materials in the behavior of seismic fracture dams, Accurate tests, and also correct definition of material behavior are a necessity. The theory of nonlinear fracture mechanics for defining the fracture area and smeared crack model for defining the develop crack, can be regarded as a proper criterion and provides us with the real behavior of the structure.

\section{References}

Abaqus theory manual and users' manual, (2009), version 6.8 .

Bazant, Z. P. and oh, B. H (1983). "Crack band theory for fracture of concrete. " Materials and Structure, 16(63): 155-177.

Bhattacharjee, S. S. and Leger, P (1992). "Concrete constitutive models for nonlinear seismic analysis of gravity dams-state-of-the art. " Canadian Journal of Civil Engineering. 19(3): 492-509.

Bhattacharjee, S. S. and Leger, P (1994). "Application of NLFM models to predict cracking in concrete gravity dams. " Journal of Structural Engineering. 120(4): 1255-1271.

Cai, Q. and Robberts, J.M. and Van Rensburg, B.W.J (2008). "Finite element fracture modeling of concrete gravity dams. " Journal of the South African Institution of Civil Engineering. 50(1): $13-24$.

Calayir, Y. and Karaton, M (2005). "Seismic fracture analysis of concrete gravity dams including damreservoir interaction. " Computers and Structures. Vol (83): 1595-1606.

Chopra, A. K. and Chakrabarti, P (1972). "The earthquake experience at Koyna dam and stress in concrete gravity dam. " Earthquake Engineering and Structural Dynamic, (1): 151-164.

Chopra, A.K (1967). "Hydrodynamic pressure on dams during earthquake, “ Journal of Engineering Mechanics Division, Vol (93), No. EM6.

El-Aidi, B. and Hall, J (1989). "Nonlinear earthquake response of concrete gravity dams part 2 : behavior. “ Vol (18): 853-865.

Seismic Response of Concrete Gravity Dams With Dam - Reservoir Interaction. “ Engineering Structures, 21, $306-315$.

Guanglun, W. and Pekau, O.A, and Chuhan, Z. and Shaomin, W (2000). "Seismic fracture analysis of concrete gravity dams based on nonlinear fracture mechanics. " Engineering Fracture Mechanics. (65): 67-87.

Hal, J. F (1988). "The dynamic and earthquake behavior of experimental behavior and observational evidence. " Soil Dynamics and Earthquake Engineering. 7(2): 58-121.

Hillerborg, A (1978). "Analysis of concrete structure by fracture mechanics. " Book.

Kolari, K (2007). "Damage mechanic model for brittle failure of transversely isotropic Solids. "Finite Element Implementation, (VTT).

Kucukarslan, S (2003). "Dam - reservoir interaction including the reservoir bottom effects in time domain. "16 Th Asce Engineering Mechanics Conference, July 16-18, University of Washington, Seattle.

Lohrasbi, A.R. and Attarnejad, R (2008). "Crack Growth in Concrete Gravity Dams Based on Discrete Crack Method. "American J. of Engineering and Applied Sciences 1 (4): 318-323.

Mirzabozorg, H. and Ghaemian, M. (2005). "Nonlinear behavior of mass concrete in three-dimensional problems using a smeared crack approach.“ Earthquake Engineering \& Structural Dynamics, (34): 247-269.

Pal, W (1976). "Seismic cracking of concrete gravity dam. " Journal of Structural Division, 102 (ST9): $1827-1844$.

Saini, S. S. and Krishna, J (1974). "Overturning of top profile of the Koyna dam during sever ground motion.

" Earthquake Engineering and Structural Dynamics, (2): 207-217.

Skrikerud, P. E., and Bachmann, H (1986). "Discrete crack modeling for dynamically loaded unreinforced concrete structure. "Earthquake Engineering and Structural Dynamics, (14): 297-315.

Uang, C. M. and Bertero, V. V (1990). “ Evaluation of seismic energy in structures. " Earthquake Engineering and Structural Dynamic, (19): 77-90. 